Pashenko Elena Anatolievna, Candidate of Law, Associate Professor of the Department of Criminal Law Disciplines, South-Russian Institute of Management - branch of Russian Presidential Academy of National Economy and Public Administration (70/54, Pushkinskaya St., Rostov-on-Don, 344002, Russian Federation). E-mail: pashenkoea@mail.ru

Saribekyan Artur Grachikovich, Graduate Student of the Department of Criminal Law Disciplines, South-Russian Institute of Management - branch of Russian Presidential Academy of National Economy and Public Administration (70/54, Pushkinskaya St., Rostov-on-Don, 344002, Russian Federation). E-mail: saribekyanarthur911@gmail.com

\title{
MANIPULATIVE INVOLVEMENT IN THE COMMISSION OF VIOLENT AND TERRORIST CRIMES AS A SIGN OF THE SOCIOCULTURAL CRISIS OF SOCIETY
}

\begin{abstract}
The authors have considered the issue of the cultural crisis and its consequences for changing the level of involvement in the commission of crimes. The analysis of involvement in the commission of crimes through the impact on human consciousness, the use of socio-economic difficulties for the submission of modified religious interpretations, justifying or prescribing violence, is offered. The danger of this situation lies in the high level of training of manipulators using technologies of psychological influence, methods of influencing the consciousness of other persons.

Keywords: subject of crime, involvement, violent crime, terrorist crimes, religious interpretation, social values, attacks against the person, propaganda content, legal crime prevention, social laws.

\section{References}

1. Kochubej M.A. Preduprezhdenie vovlecheniya molodezhi v terroristicheskie i ekstremist-skie organizacii, Mezhdunarodnaya nauchno-prakticheskaya konferenciya «Sozdanie vospitatel'noj antiterroristicheskoj i antiekstremistskoj sredy v sovremennom mire (14-15 aprelya 2016, g. Sankt-Peterburg). Elektronnyj dostup: https://www.cisatc.org/1289/134/148/8858. Data obrashcheniya 26.04.2021.

2. Kochubej M.A. Doklad na onlajn-konferencii: Ekstremizm: infovojny novogo tipa. 9 noyabrya 2020. Elektronnyj dostup: http://pressmia.ru/pressclub/20201109/952963994.html Data obrashcheniya 20.04.2021
\end{abstract}

\section{МИГРАЦИЯ КАК ДЕТЕРМИНАНТА ЭКСТРЕМИЗМА}

\author{
Смайлиев аспирант сектора уголовного права и криминологии, \\ Шамиль уголовно-исполнительного права, Институт государства и права РАН \\ тимурович (119019, Россия, г. Москва, ул. Знаменка, 10).E-mail: sham_smailiev@mail.ru
}

\section{Аннотация}

Уже долгое время экстремизм признается серьезной угрозой для личности, общества и государства. Данная статья посвящена миграционным процессам как стимулятору экстремистских настроений и детерминанте экстремистских проявлений. Автор раскрывает, что понимается под миграционными процессами и анализирует их влияние на уровень экстремизма в стране. В статье рассмотрены сложности в социальной адаптации иммигрантов, изучен вопрос их правосознания, а также обращено внимание на высокий латентный уровень преступлений экстремистской направленности, совершаемых в отношении иммигрантов. Результаты исследования расширяют знания о противодействии экстремизму и могут быть использованы на практике.

Ключевые слова: миграция, миграционные процессы, экстремизм, экстремизм в миграционных процессах, экстремизм в условиях миграции, преступления экстремистской направленности, миграционная преступность, детерминанта экстремизма, латентность преступлений экстремистской направленности.

В последние десятилетия массовый миграционный наплыв привносит с собой усиление межнациональных и межконфессиональных противоречий, обострение общественных отношений, провоцирует рост масштабов и разнообразия форм экстремистских проявлений. Слабо контролируемые и неэффективно продуманные миграционные процессы по всему 
миру оказывают огромное социально-экономическое и демографическое воздействие, а также имеют потенциал к обострению отношений между вновь прибывшим населением и коренным (оседлым) населением.

Миграционные процессы во многом становятся стимуляторами радикализации общественных настроений, побуждают к нетерпимости, проявлениям агрессии и насилия. Уместным будет замечание о том, что массовая иммиграция способствует усилению межнациональных и межконфессиональных столкновений, увеличивает напряженность в обществе, побуждает к росту экстремистских проявлений $[1$, с. 3].

Центральный и сложнейший вопрос, вызывающий бурную полемику ученных, посвятивших себя изучения явления экстремизм является вопрос о детерминантах экстремизма. Проблемы детерминации общей преступности были рассмотрены в трудах ведущих ученных в криминологии таких, как Ю.М. Антонян [2, с. 126-127], В.Н. Кудрявцев [3, с. 3], А.И. Долгова [4, с. 15], А.Э Жалинский [5, с. 165-173], И.И. Карпец [6, с. 52], Н.Ф. Кузнецова [7, с. 110] и прочие. Изучением причинного комплекса экстремизма были заняты такие ученые, как Ю.М. Антонян [8, с. 74-81], М.В. Ульянов [1, с. 59], А.В. Петрянин [9, с. 163], А.И. Долгова [10, с. 746], А.М. Багмет [11, с. 17-25], В.С. Кудрин [12, с.1-160] и другие.

Место миграции в причинном комплексе экстремизма исследователями видится поразному и не получило в настоящее время общепризнанного единства в понимании. Рассмотрим некоторые позиции ученых, исследовавших влияние миграции на экстремизм.

Л.А. Кононов и А.В. Чеботарев в качестве причин нарастания экстремистских проявлений в РФ считают усиление инокультурных, иноконфессиональных, иноэтнических миграционных потоков с их обоснованием в крупных городах отдельных субъектах страны $[13$, c. $112-114]$.

С.С. Галахов утверждает, что к числу основных факторов возникновения молодежного экстремизма в РФ относит усиление миграционных процессов, что затрагивает исторически сложившийся этнический баланс населения, следствием чего становятся проблемы в межэтнических отношениях [14, с. 98-99].

К числу детерминант экстремизма, по мнению И.И. Бикеева и А.Г. Никитина, следует отнести миграционные процессы [15, с. 53-78, 80]. Заслуживает внимание авторитетная позиция А.И. Долговой, которая причиной совершения преступлений, в том числе преступлений экстремистской направленности против мигрантов, а также самими мигрантами считала проблемы, преследующие мигрантов социально-экономического, социально-психологического и организационного характера при социализации в новой, непривычной для них общности [16, с. 711].

В Стратегии противодействия экстремизму в Российской Федерации были предусмотрены положения, предотвращающие раскол в обществе. Так, в качестве фактора, порождающего экстремистские проявления, в Стратегии противодействия экстремизму в Российской Федерации был закреплен фактор «неблагоприятной миграционной ситуации»1.

Она складывается в виду того, что мигрантам представляется непросто адаптироваться к новой среде, а сама среда не хочет адаптироваться к приезжим и не редко активно противостоит такой адаптации. Подобное противопоставление приводит к взаимному недоверию, неприязни и нежелательным конфликтам. Среди местного (коренного) населения начинают бродить идеи повышенной «криминальности», исходящей от приезжих, а среди иммигрантов идеи неприязни и недоброжелательности местного населения по отношению к ним.

Стратегия национальной безопасности, утвержденная Указом Президента РФ от 31.12.2015 г. № 683 (далее - Стратегия национальной безопасности), в качестве главных угроз национальной безопасности в области экономики выделяет на ряду с прочими угрозами «неконтролируемую и незаконную миграцию»². В целях противодействия угрозам экономической безопасности рассматриваемая Стратегия национальной безопасности призывает реализовать государственную социально-экономическую политику, предусматривающую

\footnotetext{
${ }^{1}$ См.: Указ Президента РФ от 29 мая 2020 г. № 344 «Об утверждении Стратегии противодействия экстремизму в Российской Федерации до 2025 года»

2 См.: Указ Президента РФ от 31.12.2015 N 683 «О Стратегии национальной безопасности Российской Федерации»//Собрание законодательства РФ, 04.01.2016, N 1 (часть II), ст. 212
} 
обеспечение баланса интересов коренного населения и трудовых мигрантов, в том числе иностранных граждан, с учетом их этнических, языковых и прочих различий, совершенствования миграционного учета, обоснованное территориальное распределение трудовых мигрантов исходя из потребностей регионов в трудовых ресурсах.

Исследователи до сих пор не пришли к единству во мнении о том, что считать миграцией и процессами, связанными с ней. В самом общем смысле словарь Ожегова С.И. предлагает понимать под миграцией перемещение, переселение населения как внутри одной страны, так и из одной страны в другую [17, с. 343]. Такое понятие можно принять и считать его базовым и универсальным, однако оно не предусматривает нюансов смены постоянного (или преимущественного) места жительства, срока (продолжительного или нет), на который совершается миграция, целей и прочих особенностей.

С учетом вышеизложенного, стоит обратиться к наиболее полному и отвечающему целям настоящего исследования определению социолога Л.Л. Рыбаковского. По его мнению, миграцию следует понимать в широком и узком смысле. В широком миграция включает в себя территориальное перемещение, совершающееся между разными населенными пунктами одной или нескольких административно-территориальных единиц. Продолжительность, регулярность и целевая направленность для широкого смысла миграции значения не имеет. В узком смысле миграция представляет собой вид территориального перемещения, который завершается сменой постоянного места жительства [18, с. 13].

Миграция населения в силу своей многоаспектности и неоднородности позволяет выделить виды миграции, среди которых: международная (межгосударственная) и внутренняя; легальная и нелегальная (незаконная) и прочие. По мнению профессора А.В. Петрянина миграция имеет под собой исключительно экономические предпосылки [9, с. 331]. Данное утверждение не является абсолютно верным, в виду отсутствия полноты. По преимущественной мотивации, лежащей в основе перемещения миграции населения можно выделить: экономическую (трудовая миграция); демографическую (воссоединение родственников, создание новых семей); социальную (поиск лучших условий для жизни, образовательная миграция); политическую (беженцы и прочие вынужденные переселенцы) и другие.

Вне зависимости от вида миграции, в том числе межгосударственной и внутренней, каждому из видов присуще свойство конфликтогенности, т.е. способности являться потенциальным источником этнических, межконфессиональных конфликтов, лежащих в основе экстремистских проявлений. Так, А.В. Петрянин писал о миграции: «... она стимулирует рост националистических настроений местного населения, влечет за собой возникновения условий для межнациональных конфликтов в процессе борьбы за перераспределение ресурсов» [9, с. 331-332]. Известный академик В.Н. Кудрявцев под конфликтом понимал «осознаваемое людьми столкновение противоположных интересов, стремлений, взглядов, проявляющееся в поведении» [19, с. 107]. Весьма уместно припомнить определение С.В. Алексеева, данное этническому конфликту, под которым ученый предлагал понимать конфликты, происходящие между отдельными представителями или группами в составе различных этносов [20, с. 139].

В основе рассматриваемых выше конфликтов сидит прообраз «чужого», который неустанно преследует человечество с доисторических времен. По верному замечанию профессора Ю.М. Антоняна: «Чужой существует потому, что есть свой, свои «мы». Принадлежность к «мы», т.е. к данному сообществу, определяется через «нашу» культуру, ее духовные ценности, обычаи, обряды, традиции» [21, с. 164]. Таким образом, следует искать корни межэтнических, межконфессиональных конфликтов и агрессии в архетипических установках, пронизывающих человеческую сущность и подсознание. Для религиозных фанатиков граница между своим и чужим прочерчивается верой и толкованием религиозных предписаний.

Одной из особенностей иммигрантов является их слабая правовая осведомленность об экстремизме. О роли самого права в формировании правомерного и предупреждении преступного поведения говорилось еще в советский период [22, с. 3-8]. Российское право сегодня не утратило своей функции мощного регулятора поведения, продолжает и сегодня создавать стимулы и предпосылки для принятия поведенческих решений. Однако, если мигрант не знает действующего российского законодательства в целом и в частности, законодательства, противодействующего экстремизму? Как быть в этом случае? По общему правилу незнание закона не освобождает от уголовной ответственности. 
Законодательное регулирование в области противодействия экстремизму не является исключением из общего правила и уголовная ответственность иммигрантов за совершение преступлений экстремистской направленности наступает по общим основаниям наступления уголовной ответственности. Всё же следует отметить, что непонимание и незнание уголовного закона, выступающего регулятором отношений в области противодействия экстремизму затрудняет криминологическое предупреждение, а вместе с тем и противодействие преступлениям экстремистской направленности в виду того, что иммигранты не информируются о возможных последствиях того или иного поведения (деяния), которое может квалифицироваться как экстремизм.

Должное информационное обеспечение иммигрантов, желающих пройти границы РФ, а также иммигрантов, уже находящихся на территории РФ позволит возложить ответственность за совершение преступлений экстремистской направленности на территории РФ. Результаты проведенного социологического исследования позволяют заключить, что общий уровень правосознания иммигрантов находится на низком уровне.

Общепризнано, что право является важнейшим инструментов управления поведением людей, закрепляет, регулирует и провозглашает ответственность за совершение преступлений в целом и преступлений экстремистской направленности в частности. Поведение мигранта есть процесс, протекающий во времени, в пространстве и включает в себя не только сами действия, но и предшествующие этим действиям психологические процессы и явления. Как и любой другой человеческий поступок, деяние, направленное на охраняемые законом отношения в области противодействия экстремизму, проходит в своем развитии определенные этапы: как внутренние (формирование элементов деяния), так и внешние (осуществления деяния вовне). Нельзя не согласиться с академиком В.Н. Кудрявцевым: «Вообще всякий сознательный акт поведения почти всегда подготовлен более или менее длительным процессом формирования мотивов, планирования и принятия решения о его осуществлении. Ему предшествует ряд этапов психологической деятельности субъекта, которые постепенно формируют направленность поступка и его фактическое выполнение» [22, с. 18].

Не стоит впадать в крайность и переоценивать роль, значение права и считать, что только право способно полностью диктовать, какое поведение нужно выбирать представителям общества. Следует отметить, что право идет в дополнение к экономическим, политическим, культурным и социальным условиям жизни как коренного населения, так и вновь прибывшего (иммигрантов). Осознание норм, регулирующих отношения в области противодействия экстремизму, безусловно является стимулятором субъектов к правомерным поступкам и не совершению экстремистских деяний. Информационное значение в противодействии преступлениям экстремистской направленности сложно переоценить. Знание основ экстремистского законодательства способно оказать предупреждающее значение как для граждан РФ, так и для иммигрантов по следующим основаниям:

1) Уяснение позиции государства по вопросам, связанным с экстремизмом;

2) Ценностная нагрузка, содержащаяся в нормах законодательства посвящённого противодействию экстремизму, обладающей большой воспитательной силой;

3) Превентивное воздействие от знания и уяснения карательных санкций за экстремистские проявления;

4) Незнание правовых предписаний в области противодействия экстремизму - одна из причин их нарушения.

На основании вышеизложенного предлагается информирование населения, взаимодействующегос иммигрантами, а также информирование самих иммигрантов по следующим элементам уголовно-правовых и административных предписаний, обеспечивающих противодействие экстремизму:

1) Понимание основных признаков экстремистских деяний;

2) Уяснение общественной опасности и противоправности экстремистских деяний;

3) Представление о санкциях, карающих за совершение экстремистских деяний.

Отдельные авторы, рассматривая состояние и динамику насильственных преступлений экстремистской направленности, указывали на низкий удельный вес насильственной экстремистской преступности среди общей преступности, регистрируемой в стране, - этим самым недооценивая разрушительную мощь, вредоносность, общественную опасность и 
преступный результат для личности, общества и государства от экстремистских деяний $[1$, c. 41]. Весьма кстати будет вспомнить Стратегию противодействия экстремизму в Российской Федерации, в которой декларируется «Количество преступлений экстремистской направленности достаточно мало по сравнению с общим количеством иных совершаемых на территории Российской Федерации преступлений, однако каждое такое преступление способно вызвать повышенный общественный резонанс и дестабилизировать внутриполитическую и социальную обстановку как в отдельном регионе, так и в стране в целом»1.

Немаловажным остается вопрос об уровне латентности преступлений экстремистской направленности. О высоком уровне искусственной латентности преступлений экстремистской направленности уже утверждалось в научных кругах [23, с. 22;]. А.В. Петрянин, исследовав практические проблемы применения норм, касающихся противодействия экстремизму, выделил ряд причин высокого уровня латентности преступлений экстремистской направленности, среди которых отметил правовой нигилизм и широкомасштабную миграцию [9, с. 324]. Во многих случаях иммигранты не спешат в обстоятельствах претерпевания актов дискриминации, непосредственно выраженных в форме насилия и вражды обращаться с заявлениями в правоохранительные органы. До общественности и правоохранительных органов, как правило, доходит лишь незначительная часть рассматриваемых явлений, которые в большей мере совершаются демонстративно, вызывая общественный резонанс. А. Кутьин в ходе исследования положения нелегальных иммигрантов отмечал высокую распространенность трудовых форм эксплуатации (задержка или невыплата заработной платы и прочеe), принуждение к секс-услугам, психологическое насилие, угрозы, шантаж, изъятие паспортов, ограничение свободы передвижений и прочие проявления [24, c. 35].

Особую сложность вызывает вопрос о зависимости изменения числа мигрантов от изменения числа преступлений экстремистской направленности. Незаконная миграция, которая не поддается четкому количественному определению, а также отмеченный ранее высокий уровень латентности преступлений экстремистской направленности, делают весьма проблематичным выявление тенденций и зависимостей между рассматриваемыми явлениями. Кажется верным утверждение М.В. Ульянова о высоких показателях зарегистрированных преступлений экстремистской направленности в Москве, Московской области, СанктПетербурге, Краснодарском крае и Новосибирской области, поскольку указанные регионы являются центрами миграционного притока РФ [1, с. 63].

Результатом исследования статистических показателей десятков государств Европейского Союза стало знание о том, что уровень распространения «преступлений ненависти» не столько зависит от экономических факторов, сколько от пропорциональности размера иммигрантской общины. Причем, в ряде государств большее распространение получили преступления со стороны мигрантов в отношении местного населения, а не наоборот [25, с. 139-160].

По данным, обнародованным Генеральной прокуратурой РФ, с 2016 года в стране замечено снижение преступности среди мигрантов (с 43,9 тысяч преступлений до 34, 4 тысяч преступлений). Большинство лиц, совершивших преступления, являются гражданами бывших союзных республик. Почти треть преступлений пришлись на Москву и Московскую область (11,5 тыс. преступлений). В столице наблюдается увеличение на 11,3 \% преступлений среди мигрантов². По итогам проведенного анализа, М.В. Ульяновым были получены следующие сведения: Около 50 \% насильственных преступлений экстремистской направленности были совершены в отношении иностранных граждан, большинство из которых являются гражданами главных доноров трудовой миграции: Киргизия, Узбекистан, Таджикистан и прочие [1, с. 41].

Еще в советское время академиком В.Н. Кудрявцевым было указано, что важнейшей задачей криминологии является глубокое раскрытие причин преступности в обществе [3, c. 3]. Раскрытие детерминант экстремизма послужит верной и прочной основой эффективной разработки мер по предупреждению и борьбе с преступностью экстремистского характера. Современное развитие общественных отношений, изменения, вызванные глобализацией общества, когда привязка человека к определенной географической территории теряет

\footnotetext{
1 Указ Президента РФ от 29 мая 2020 г. № 344 «Об утверждении Стратегии противодействия экстремизму в Российской Федерации до 2025 года»

${ }^{2}$ См.: Портал правовой статистики Генеральной прокуратуры PФ. URL: http://crimestat.ru
} 
былое значение, а границы между государствами постепенно стираются, подчеркивает остроту в потребности в глубокой, своевременной, полной, качественной оценке экстремистской обстановки. Изучение характера и причин экстремистской обстановки в условиях миграции, достоверное отслеживание ее изменений и тенденций, выявление актуальных проблем, краткосрочное и долгосрочное прогнозирование и планирование миграционных процессов и своевременное, научное обоснованное законодательное регулирование во многом отражает сегодняшнюю потребность законопослушного большинства российского общества.

Исходя из проведенных социологических исследований, можно сделать вполне логичный вывод о том, что миграция населения выступает в качестве одной из основных детерминант экстремистских деяний. Однако официальная статистика зарегистрированных преступлений экстремистской направленности и статистика, показывающая число мигрантов, находящихся в пределах территории РФ, сильно занижена. Расхождение между официальными данными статистики и фактическим положением побуждает к реальному изучению динамики преступлений экстремистской направленности в зависимости от интенсивности миграционного потока.

В качестве отдельного направления по противодействию экстремизму следует выделить эффективное планирование и реализацию миграционной политики, исходя из чего прослеживается потребность в:

1) укреплении толерантности;

2) выработке научно обоснованных способов адаптации иммигрантов;

3) повышении уровня правосознания;

4) четком в планировании распределения квот для предоставления мигрантам, с учетом внутренней безработицы и нехватки рабочих мест для граждан РФ;

5) усилении мер по противодействию незаконной миграции;

6) контроле за целенаправленной профилактической деятельностью национальных (этнических) диаспор, расположенных в регионах, на предмет их превентивного призыва к терпимости, отказу от насилия, агрессии и жестокости по отношению к представителям других этносов, религий, рас и прочих отличительных особенностей.

\section{Литература}

1. Ульянов М.В. Миграционные процессы в системе детерминант экстремистской преступности: монография / Под ред. докт. юрид. наук, проф. В.В. Меркурьева. М.: Юрлитинформ, 2019. 176 c.

2. Антонян Ю.М. Почему люди совершают преступления. Причины преступности. М., 2006. $304 \mathrm{c}$.

3. Кудрявцев B.Н. Причинность в криминологии (О структуре индивидуального преступного поведения). М.: «Юридическая литература», 1968. 176 с.

4. Долгова А.И. Криминологические оценки организованной преступности и коррупции, правовые баталии и национальная безопасность. М., 2011. 665 с.

5. Жалинский А.Э. Обновление криминологии// Российский криминологический взгляд. 2011. № 2.

6. Карпец И.И. Современные проблемы уголовного права и криминологии. М., 1976. 224 с.

7. Кузнецова Н.Ф. Проблемы криминологической детерминации / Под ред. Кудрявцева В.Н. М.: Изд-во Моск. ун-та, 1984. 208 с.

8. Экстремизм и его причины: монография / Ю.М. Антонян, А.В. Ростокинский, Я.И. Гилинский [и др.]; под ред. Ю. М. Антоняна. М.: Логос, 2020. 312 с.

9. Петрянин А.В. Концептуальные основы противодействия преступлениям экстремистской направленности: теоретико-прикладное исследование : диссертация ... доктора юридических наук : 12.00.08. Нижний Новгород, 2015. 501 с.

10. Криминология : учебник / Под общ. ред. А. И. Долговой. 4-е изд., перераб. и доп. М.: Норма: ИНФРА-М, 2020. 1008 с.

11. Молодежный экстремизм. Понятие и противодействие : учебное пособие для студентов вузов, обучающихся по направлению подготовки «Юриспруденция» по специальностям «Правовое обеспечение национальной безопасности», «Правоохранительная деятельность» / А.М. Багмет, В.В. Бычков, Л.В. Голоскоков ; под общ. ред. А.М. Багмета. М.: ЮНИТИДАНА, 2020. 319 c. 
12. Кудрин В.С., Юдина А.И. Молодежный экстремизм: причины возникновения, технологии предупреждения : учеб. пособие для студентов. Кемерово : Кемеров. гос. ин-т культуры, 2016. $160 \mathrm{c}$.

13. Кононов Л.А., Чеботарев А.В. Взаимосвязь экстремизма и современных миграционных процессов как предмет политологического исследования // Государственное управление. Электронный вестник Выпуск № 70. Октябрь 2018.

14. Галахов С.С. и др. Экстремизм в современном обществе. Социальные и криминологические аспекты: монография. М., 2014.

15. Бикеев И.И., Никитин А.Г. Экстремизм: междисциплинарное правовое исследование. Казань, 2011.

16. Криминология / Под общ. ред. А.И. Долговой. М., 1999. 779 с.

17. Ожегов С.И. Словарь русского языка: около 60000 слов и фразеологических выражений. 25-е изд., испр. и доп. / общ. ред. проф. Л.И. Скворцова. М.: Оникс; Мир и образование, 2007. $972 \mathrm{c}$.

18. Рыбаковский Л.Л. Миграция населения (вопросы теории): монография. М., 2003. 239 с.

19. Кудрявцев В.Н. Причины правонарушений. М., 1976. 285 с.

20. Конфликтология: учеб. Пособие для бакалавров / Отв. ред. А.Я. Гуськов. М., 2013. 171 с.

21. Природа этнорелигиозного терроризма / Ю.М. Антонян, Г.И. Белокуров, А.К. Боковиков и др.; Под ред. Ю.М. Антоняна. М.: Аспект Пресс, 2008. 364 с.

22. Кудрявцев В.Н. Право и поведение. М.: Юрид. лит., 1978. 192 с.

23. Фридинский С.Н. Борьба с экстремизмом : Уголовно-правовой и криминологический аспекты : автореферат дис. ... кандидата юридических наук : 12.00 .08 / Рост. юрид. ин-т МВД РФ. Ростов-на-Дону, 2003. 28 с.

24. Кутьин А.Д. Виктимология миграционных процессов в России // Профессионал. 2007. № 2 .

25. Van Kesteren J. Assessing the risk and prevalence of hate crime victimization in Western Europe // International Review of Victimology. 2016. V. 22 (2). P. 139-160.

Smailiev Shamil Timurovich, Postgraduate Student of Correspondence Course of the Sector of Criminal Law and Criminology, Criminal Executive Law, Institute of State and Law of the Russian Academy of Sciences (10, Znamenka St., Moscow, 119019, Russian Federation).E-mail:sham_smailiev@mail.ru

\title{
MIGRATION AS A DETERMINANT OF EXTREMISM
}

\begin{abstract}
For a long time, extremism has been recognized as a serious threat to individuals, society and the state. This article is devoted to migration processes as a stimulator of extremist sentiments and a determinant of extremist manifestations. The author reveals what is meant by migration processes and analyzes their impact on the level of extremism in the country. The article examines the difficulties in the social adaptation of immigrants, studies the issue of their legal awareness, and also draws attention to the high latent level of extremist crimes committed against immigrants. The research results expand knowledge about countering extremism and can be used in practice.

Keywords: migration, migration processes, extremism, extremism in migration processes, extremism in the context of migration, extremist crimes, migration crime, the determinant of extremism, latency of extremist crimes.

\section{References}

1. Ul'yanov M.V. Migracionnye processy v sisteme determinant ekstremistskoj prestupnosti: monografiya / Pod red. dokt. yurid. nauk, prof. V.V. Merkur'eva. M.: YUrlitinform, 2019. 176 p.

2. Antonyan YU.M. Pochemu lyudi sovershayut prestupleniya. Prichiny prestupnosti. M., 2006. 304 p.

3. Kudryavcev V.N. Prichinnost' v kriminologii (O strukture individual'nogo prestupnogo povedeniya). M.: «YUridicheskaya literatura», 1968. 176 p.

4. Dolgova A.I. Kriminologicheskie ocenki organizovannoj prestupnosti i korrupcii, pravovye batalii i nacional'naya bezopasnost'. M., 2011. 665 p.

5. ZHalinskij A.E. Obnovlenie kriminologii// Rossijskij kriminologicheskij vzglyad. 2011. № 2 .

6. Karpec I.I. Sovremennye problemy ugolovnogo prava i kriminologii. M., 1976. 224 p.
\end{abstract}


7. Kuznecova N.F. Problemy kriminologicheskoj determinacii / Pod red. Kudryavceva V.N. M.: Izdvo Mosk. un-ta, 1984. 208 p.

8. Ekstremizm i ego prichiny : monografiya / YU. M. Antonyan, A. V. Rostokinskij, YA. I. Gilinskij [i dr.] ; pod red. YU. M. Antonyana. M.: Logos, 2020. 312 p.

9. Petryanin A.V. Konceptual'nye osnovy protivodejstviya prestupleniyam ekstremistskoj napravlennosti: teoretiko-prikladnoe issledovanie : dissertaciya ... doktora yuridicheskih nauk : 12.00.08. Nizhnij Novgorod, 2015. 501 p.

10. Kriminologiya : uchebnik / Pod obshch. red. A. I. Dolgovoj. 4-e izd., pererab. i dop. M.: Norma: INFRA-M, 2020. $1008 \mathrm{p}$.

11. Molodezhnyj ekstremizm. Ponyatie i protivodejstvie : uchebnoe posobie dlya studentov vuzov, obuchayushchihsya po napravleniyu podgotovki «YUrisprudenciya» po special'nostyam «Pravovoe obespechenie nacional'noj bezopasnosti», «Pravoohranitel'naya deyatel'nost'» / A.M. Bagmet, V.V. Bychkov, L.V. Goloskokov ; pod obshch. red. A.M. Bagmeta. M.: YUNITI-DANA, 2020. 319 p.

12. Kudrin V.S., YUdina A.I. Molodezhnyj ekstremizm: prichiny vozniknoveniya, tekhnologii preduprezhdeniya : ucheb. posobie dlya studentov. Kemerovo: Kemerov. gos. in-t kul'tury, 2016. $160 \mathrm{p}$.

13. Kononov L.A., CHebotarev A.V. Vzaimosvyaz' ekstremizma i sovremennyh migracionnyh processov kak predmet politologicheskogo issledovaniya // Gosudarstvennoe upravlenie. Elektronnyj vestnik Vypusk № 70. Oktyabr' 2018.

14. Galahov S.S. i dr. Ekstremizm v sovremennom obshchestve. Social'nye i kriminologicheskie aspekty: monografiya. M., 2014.

15. Bikeev I.I., Nikitin A.G. Ekstremizm: mezhdisciplinarnoe pravovoe issledovanie. Kazan', 2011.

16. Kriminologiya / Pod obshch. red. A.I. Dolgovoj. M., 1999. 779 p.

17. Ozhegov S.I. Slovar' russkogo yazyka: okolo 60000 slov i frazeologicheskih vyrazhenij. 25-e izd., ispr. i dop. / obshch. red. prof. L.I. Skvorcova. M.: Oniks; Mir i obrazovanie, 2007. 972 p.

18. Rybakovskij L.L. Migraciya naseleniya (voprosy teorii): monografiya. M., 2003. 239 p.

19. Kudryavcev V.N. Prichiny pravonarushenij. M., 1976. 285 p.

20. Konfliktologiya: ucheb. Posobie dlya bakalavrov / Otv. red. A.YA. Gus'kov. M., 2013. 171 p.

21. Priroda etnoreligioznogo terrorizma / YU.M. Antonyan, G.I. Belokurov, A.K. Bokovikov i dr.; Pod red. YU.M. Antonyana. M.: Aspekt Press, 2008. 364 p.

22. Kudryavcev V.N. Pravo i povedenie. M.: YUrid. lit., 1978. 192 p.

23. Fridinskij S.N. Bor'ba s ekstremizmom : Ugolovno-pravovoj i kriminologicheskij aspekty : avtoreferat dis. ... kandidata yuridicheskih nauk : 12.00 .08 / Rost. yurid. in-t MVD RF. Rostov-naDonu, 2003. 28 p.

24. Kut'in A.D. Viktimologiya migracionnyh processov v Rossii // Professional. 2007. № 2.

25. Van Kesteren J. Assessing the risk and prevalence of hate crime victimization in Western Europe // International Review of Victimology. 2016. V. 22 (2). P. 139-160. 